\title{
Reforms and Economic Growth in Transition Economies: Complementarity, Sequencing and Speed
}

\author{
Karsten Staehr ${ }^{1}$ \\ University of Tartu
}

\begin{abstract}
This paper considers the effects of sequencing and reform speed on output performance in transition countries. These largely unsettled issues are addressed using principal component techniques to construct reform clusters and by explicit tests of speed effects. The results indicate that broad-based reforms are good for output growth, but so is a policy of liberalisation and small-scale privatisation without structural reforms. Conversely, large-scale privatisation without adjoining reforms, market opening without supporting reforms and bank liberalisation without enterprise restructuring affect growth negatively. Swift reform policies allow transition countries to benefit from higher growth for longer time. The speed of reforms appears otherwise to have little effect on growth in the short and medium term.
\end{abstract}

JEL Classification: P21, P30, C33, H11

Keywords: Economic reforms, growth, principal components, gradualism versus big-bang

\section{Introduction}

A defining theme in transition economics is Adam Smith's centuries old question: How do countries become rich? From the start of reforms in the early 1990s, the most important policy objective in the transition countries was to raise living standards by boosting output. The debate over the choice of reform strategy was fuelled by the deep production falls experienced in all transition economies. Adam Smith's question essentially epitomises the discussion of which reform strategy is most likely to be successful.

Case studies provide valuable insights into the effects of reforms on short-term growth and other variables of interest. ${ }^{2}$ They allow a detailed analysis of reforms, taking into account political and socio-economic factors. Unfortunately, case studies do not necessarily produce results that can be broadly generalised and their conclusions may be influenced unduly by recent experience. ${ }^{3}$

The most important approach to analysing the effects of reforms on output growth is cross-section or panel data estimations, explaining the short-term output

\footnotetext{
${ }^{1}$ University of Tartu, Lossi 3-319, 51003 Tartu, Estonia. E-mail: karsten.staehr@ut.ee. I would like to thank editors Michael Keren and Vittorio Valli and an anonymous referee of the European Journal of Comparative Economics for helpful comments and suggestions. I am also grateful for feedback from Abdur Chowdury, Balazs Egert, Tuuli Koivu, Iikka Korhonen, Jukka Pirttila and Jouko Rautava as well as seminar participants at BOFIT, the Central Bank of Norway and University of Tartu.

${ }^{2}$ See Campos and Coricelli (2002) footnote 47 for a listing of case studies considering the impact of reforms on growth and other economic variables. IMF Article IV consultations and the OECD Economic Surveys routinely discuss country performance in the light of reforms undertaken and point out areas of "unfinished reforms" that may impede growth.

3 The assessment of the large-scale voucher privatisation in the Czech Republic illustrates this point. The method was initially considered highly successful as the Czech economy boomed in the mid-1990s, but later discredited following the country's poor performance in the late 1990s.
} 
growth by variables reflecting economic reforms while controlling for other factors. The first contributions, appearing in the mid-1990s, were the starting point for an extensive literature. Nevertheless, a number of issues related to the choice of reform strategy and its impact on growth remain largely unresolved, in particular:

- What is the relative importance of individual reform elements?

- Can different reform elements substitute for each other or are some reforms complementary in the sense that their implementation has to be synchronised or sequenced to obtain favourable results?

- How rapidly should reforms be implemented?

The lack of firm empirical evidence on these questions is unfortunate as it hampers the ex post evaluation of the different reform strategies carried out in the transition countries. Moreover, policymakers in all transition countries continue to face sequencing and speed issues when designing reform packages (Nsouli et al., 2002).

The questions also take centre place in the occasionally heated debate on reform strategy, e.g. World Bank (1996) and Stiglitz (2001). ${ }^{4}$ Two camps have emerged. One camp - under labels like "big-bang", "cold turkey" or "market fundamentalism" favours rapid and comprehensive reforms. The basic premise is that reforms should progress as fast and on as many fronts as possible because various reform elements can (at least, to some extent) substitute for each other. The other camp - under labels like "gradualism" or "evolutionary-institutionalist perspective" -emphasises timing and sequencing of specific reforms and tends to favour slower implementation of reforms. Complementarities between specific sets of reforms are seen as important, so reforms must be sequenced, i.e. certain reforms are prerequisites to other reforms.

We seek, within the framework of growth regressions, to make progress on the three contentious issues above. ${ }^{5}$ First, we apply principal component analysis on (stacked) reform indices to identify "reform clusters". This allows a deeper discussion of the overall design of reform programs in transition economies. Second, we address inference problems stemming from the correlation of many reform variables. This facilitates identification of which reforms are most important for economic growth. Third, we use estimation with reform clusters as right-hand side variables to reveal complementarities between reform elements. This provides insight into the reform sequencing issue. Fourth, the importance of speed is addressed in considerable detail. Several direct tests are devised and implemented.

This paper uses the term output growth in the same way as most other papers in this literature, vi\% as the annual change in output during the period transition. In the nature of the case, long-term changes in output cannot be analysed for the transition economies as the transition process started in the early 1990s.

The paper is organised as follows: Section 2 reviews the literature of growth estimations for transition economies. Section 3 discusses selection of an econometric

\footnotetext{
4 Wolf (1999) and Roland (2001) survey the debate, the latter with an emphasis on political economy arguments. See also IMF (2000) for an overview and references. The debate is based on different assessments of how both transition and market economies function. The approaches have divergent views on the political economy of reform, in particular the conditions for maintaining reform momentum. There are also different perspectives on the amount of uncertainty linked to reforms and how to manage this uncertainty. It is essentially an empirical problem to evaluate which reform strategy - including choice of specific reforms, sequencing and speed - yields the best results.

${ }^{5}$ Note that the discussion on reform strategy raises many issues besides growth effects. These include distribution, political consolidation and long-term sustainability.
} 
model and variables. Section 4 analyses the correlation pattern of reform variables and derives reform clusters. Section 5 estimates the impact of reform clusters and control variables on growth. Section 6 tests how reform speed affects growth. Section 7 concludes.

\section{Growth regressions for transition economies}

The literature on growth regressions for transition economies seeks to explain the countries' short-term growth performance by miscellaneous variables that reflect e.g. economic reforms, initial conditions or economic shocks. A diverse range of variables has been employed for right-hand side variables, while variables accounting for accumulation of human and physical capital are typically omitted. ${ }^{6}$ This approach owes its intellectual debt to the "new growth" literature of the 1990s (Havrylyshyn et al., 1998).

Fischer et al. (1996a) initiated the literature. Their analysis used a panel of annual data 1992-94 for 25 transition economies. Monetary stabilisation as captured by budget balance and an exchange rate regime dummy were positively linked with growth. ${ }^{7}$ Transition reforms were measured by a "cumulative liberalisation index", which weighted scores for price liberalisation, trade liberalisation, privatisation and banking reform, each year calculated by accumulating the scores for all previous years of reform. ${ }^{8}$ The cumulative liberalisation index also proved beneficial to growth.

Fischer et al. (1996a) has been succeeded by a host of papers estimating growth regressions for transition economies. The papers are too numerous to cite, but survey papers have recently synthesised the literature. Havrylyshyn (2001) focuses entirely on growth regressions while Fischer and Sahay (2000), Campos and Coricelli (2002), World Bank (2002) and EBRD (2004, ch. 1) frame the results from regression analyses in broader discussions. ${ }^{9}$ The survey papers generally agree on the following:

- All transition economies experienced an initial steep fall in production, even those undertaking very limited reforms. Clearly, reforms cannot explain the output drop.

- Traditional factor analysis plays no role in explaining the growth performance in transition economies.

- Initial conditions, e.g. the structure and the economic development of the planned economy, affect the growth performance. The importance of initial conditions appears to diminish over time.

- Nearly all papers confirm the main findings in Fischer et al. (1996a). Monetary stabilisation and reforms that change the structure of the economy are positively correlated with growth performance. Some studies find an immediate negative effect of liberalisation and structural reforms, while others do not.

\footnotetext{
6 Wacziarg (2002, p. 907) characterises the methodology as "...a now well-established tradition of throwing every variable under the sun into the kitchen sink of growth regressions."

7 Fischer et al. (1996a) argue that monetary stabilisation is a "prerequisite" for growth in transition economies. It is difficult to see how they arrive at this conclusion as the variables for monetary stabilisation enter additively in their estimations.

${ }^{8}$ This method of accumulating the scores implies that even if there is no change in reforms from a certain year, the cumulative liberalisation will still increase year after year.

${ }^{9}$ Havrylyshyn (2001) tabulates many of the studies, their empirical methods and the main results.
} 
These findings have generally been confirmed by studies employing different samples, control variables and econometric methods (Havrylyshyn, 2001). ${ }^{10}$ The results appear robust and the literature has successfully framed the debate on reforms among academics and policymakers (e.g. World Bank, 1996). However, a number of important issues remain unresolved, including the importance of: (i) specific reform elements, (ii) the sequencing and complementarity of reform elements, and (iii) the speed at which reforms should be implemented.

(i): There is little research on the relative importance of specific types of reforms. Many studies use the sum or average of various reform indices and show that this measure is correlated with growth. Other studies employ a tiny set of variables and stress the importance of one or a few factors on growth. Havrylyshyn et al. (1998) consider the importance of specific reform elements. They find that generally an aggregate index performs best whereas parameters to individual reform elements are estimated very imprecisely. Berg et al. (1999) also test for the effect of specific reform elements, obtaining inconclusive results dependent on the specification of the regression model.

Only a few studies succeed in pinpointing specific reforms important in promoting growth. The main reason is that the individual reform indices are generally highly correlated. Countries that liberalise quickly typically also proceed with privatisation and structural reforms. Multicollinearity leads to imprecisely estimated parameters, and exclusion of an insignificant reform index can change the sign of other parameter estimates. The problem is aggravated by poor data quality, little a priori theoretical guidance and possible changes in the growth process during transition.

(ii) The importance of sequencing and complementarity has stirred much controversy. Havrylyshyn (2001, p. 79) states in the conclusion: "The least well resolved - and arguably most important - continuing debate concerns the timing and sequencing of institutional reforms" (italics of source). The phrase "institutional reforms" should here be interpreted as all changes to the institutional structure of the economy, e.g. the dismantling of the planning system (liberalisation), the transfer of property rights (privatisation) and the creation of new institutions (structural reforms).

Most studies yield limited insights into these issues. The sum or average of various reform indices used in many studies implies perfect substitutability of reforms, i.e. lagging reforms in one area can be fully counterbalanced by faster reforms in other areas (Correa, 2002). Studies that focus on one or a few variables essentially assert that these few variables are indispensable and implicitly assume perfect complementarity.

A few studies directly address the issue of reform complementarity and sequencing. Havrylyshyn et al. (1998) find that the aggregate reform index generally is more important than any specific index: when replacing the aggregate index with any of its three components individually, the fit deteriorates. This could be interpreted as an indication that the overall reform package is what matters for growth, i.e. reforms are complementary and in this sense sequencing matters. Zinnes et al. (2001) include an interaction term between a privatisation variable and a variable that captures corporate

10 A recent study has questioned this conclusion. Radulescu \& and Barlow (2002) question this conclusion. They employ specific modelling and extreme bounds analysis and find a stable relationship between inflation stabilisation and growth, but not between transition reforms and growth. The applicability of their analysis is, however, limited as many of their right-hand side variables are highly correlated. Multicollinearity implies that sequential elimination of explanatory variables and extreme bounds analyses are unreliable as the elimination tests have low power. 
sector reforms. They find that, while privatisation alone has no effect on growth, privatisation combined with corporate reforms has a positive effect.

(iii) The importance of the speed at which reforms are implemented is an issue, which remains largely unresolved. Havrylyshyn (2001, p. 80) states with reference to the debate on sequencing: "An equally difficult debate continues on the speed of reforms ..." (author's italics). Only a limited number of papers seek to test directly whether the speed of reform implementation has an effect on output performance.

Most studies find that that the level of reforms affects growth positively. From this follows trivially that speedy reform is advantageous, since the country will benefit from higher growth from an early stage. This inference, however, says little about the impact of the speed with which reforms are changed. Also, we would generally be interested in effects of speedy reform over and above this level effect.

Other papers, e.g. de Melo et al. (1997), employ the cumulative liberalisation index used in Fischer et al. (1996a) and argue that a positive and significant parameter estimate indicates that speedy reforms are beneficial. Per construction, the cumulative liberalisation index captures the current level of reform in addition to the sum of previous reform levels. The sum of previous reforms contains information about the extent of previous reforms undertaken earlier, but is an imperfect indicator of the speed at which reforms are implemented. ${ }^{11}$ Besides, the use of the cumulative liberalisation index does not allow a separation of the effects of the reform level and earlier reforms.

Berg et al. (1999) seek to remedy the latter problem by including separate terms for the initial reform level, for the current reform level, and for a weighted sum of lagged reform levels. They find that the parameter to the weighted sum of lagged reforms is significant and positive, and take this as a sign that there are extra benefits of (early) reforms. However, as also discussed in Berg et al. (1999), the discounted sum of reforms is at best a rather indirect measure of the reform speed.

Heybey and Murell (1999) find that the speed of reforms has no effect on growth when one controls for endogeneity by taking into account the effect of growth on reforms. The results are derived in a cross-country estimation with few observations, and the choice of instrument variables can be questioned. They use the change of reforms as a proxy for the speed of reforms. It is, as argued above, a very indirect measure of speed.

Wolf (1999) divides transition countries into three groups (radical reformers, gradual reformers and lagging reformers), based on reform progress at the early stages of transition. He shows that a dummy, which is equal to 1 for the countries belonging to the group of fast reformers, is insignificant when controlling for the reform level.

These mostly indirect tests of speed effects and their inconclusive results stem from two complications. First, it is difficult to construct testable hypotheses for an often vaguely defined concept of reform speed. Second, empirical implementation is difficult because of the problem of devising well-specified growth regressions from the few available observations.

In sum, a number of issues related to the growth effects of reforms in transition economies are still debated, in particular, the importance of specific reforms, the importance of sequencing and complementarity and the effect of reform speed. The

\footnotetext{
${ }^{11}$ A country, which has reform level 1 in the first two periods and then increases the level to 4 in the third period, will after the third year have a cumulative liberalisation index of 6 . A country having a reform level equal 1 in the first year, 2 in the second year and 3 in the third year, would also have a cumulative liberalisation index of 6 after three years.
} 
inconclusive results are partly the consequence of econometric difficulties stemming from specification problems and highly correlated data series.

\section{Estimation model and data}

\subsection{Choosing a model}

Econometric modelling of the link between reforms and economic performance inevitably appears simplistic in light of the complexities of the transition process. Figure 1 presents a stylised model of the factors determining economic performance. Initial conditions can affect economic performance directly, but might also influence the choice of reforms and vulnerability to exogenous shocks. The choice of economic reforms influences economic performance, but there might also be a feedback from performance to reforms, whereby the reforms affect the prevalence and seriousness of various shocks. Sachs et al. (2000), Campos and Coricelli (2002) and EBRD (2004, ch. 1) give broader discussions of the factors influencing the growth process in transition countries.

Figure 1. A stylised model of economic performance

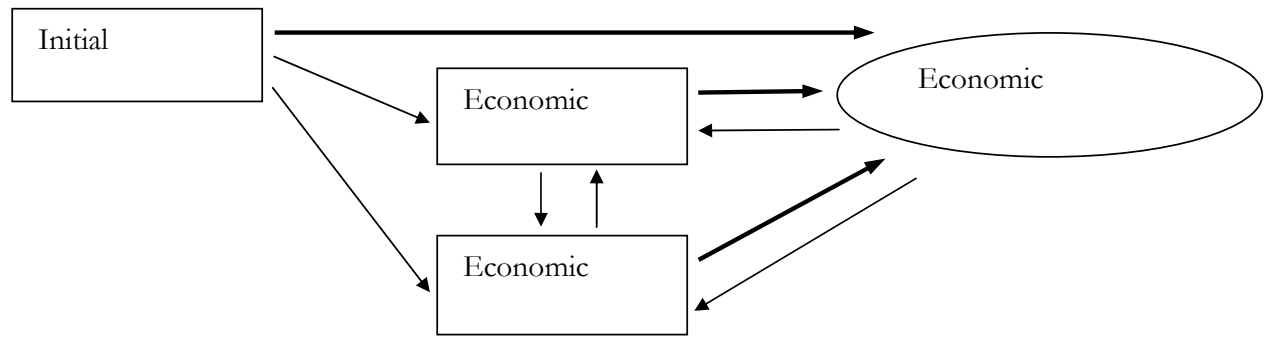

In general, one cannot expect to model all factors determining economic performance, including the endogeneity of policy formation and shock vulnerability. The focus of this study is the effect of reform and reform strategies on growth and to keep complexities at a minimum, we choose not to model explicitly the policy formation process. We consider one-equation panel regressions with the growth rate as the left-hand side variable and different explanatory variables on the right-hand side. The right-hand variables include reform variables, shocks and initial conditions and - as argued below these variables will be considered weakly exogenous in determining the growth rate.

We treat the economic reform indices as weakly exogenous and enter different transformations of the reform indices on the right-hand side of the regressions. This follows the view of Berg et al. (1999) who argue that policymakers ultimately decide which reforms to implement. A number of studies have shown that the possible endogeneity bias from treating the reform variables as weakly exogenous is rather unimportant, i.e. that the marginal effect of reforms on growth is broadly similar whether or not one seeks to correct for the endogeneity bias. ${ }^{12}$

12 Heybey and Murrell (1999) estimate growth and reform level in a system. Wolf (1999) instruments the reform variable. Berg et al. (1999) use IMF targets to instrument right hand variables, but find no noteworthy difference between the instrumented and the non-instrumented regressions. 
Initial conditions in transition countries varied tremendously. Uzbekistan emerged from the Soviet Union as a mainly agricultural country with disrupted trade links. Hungary, in contrast, has industrialised and even implemented some marketoriented reforms. We generally expect initial conditions to be country specific so that the effect of initial conditions can be soaked up with fixed-effect dummies. However, we also perform regressions with variables reflecting initial conditions.

The only control employed for exogenous shocks is a war dummy. It is mainly introduced to ensure that the numerically huge negative growth rates experienced in a number of CIS and Balkan countries during war and civil unrest do not lead to extreme outliers that unduly affect results. Havrylyshyn (2001) concludes in his survey that controls for shocks and initial conditions only affect slightly the estimated marginal effects of reforms.

The choice of specific reform variables to be included on the right-hand side is difficult. We focus on eight reform indices assembled and published by the European Bank for Reconstruction and Development (EBRD). Together with a variable reflecting nominal stability, these variables broadly cover the four main areas of reforms: liberalisation, stabilisation, privatisation and structural reforms. Further, the EBRD indices are available for the period 1989-2001, which permits a long estimation sample.

A host of other variables have been included in growth regressions for transition countries, e.g. measures capturing the institutional environment, governance and government ability, legal protection and social capital. It is relatively easy to find theoretical / intuitive arguments for including almost any variable. Having only a limited number of data points, one is forced to make difficult - and somewhat arbitrary decisions on which variables to include and exclude.

We focus on reform policies of a rather specific character. The EBRD indices are "established" in the literature, allow a long sample and are all collected by the same source. By omitting broader-based measures of transitional readiness, we avoid complex issues related to the quality and interpretation of such variables. The many variables are closely related and might to some extent be captured in the EBRD indices. For example, Ahrens and Meurers (2002) show that measures of governance quality are likely to affect economic outcome only via their impact on economic policies. Havrylyshyn and van Rooden (2000) show that nearly all of a large number of institutional indicators are strongly correlated with the EBRD indices.

\subsection{The data set}

The data set is a balanced panel consisting of annual data for 25 transition economies from 1989 to 2001. Bosnia-Herzegovina and Yugoslavia are excluded because of data problems. As in most other studies, the Asian transition countries (Mongolia, Vietnam and China) are not included in the data set. ${ }^{13}$

The left-hand side variable, $G$, is the growth rate of the gross domestic product, expressed as per cent per year. The EBRD data source (various issues) relies on official statistics, so data quality problems imply that output growth at the beginning of the transition is probably underestimated as new private sector activities are only partly covered (Aslund 2002, ch. 4). Data that is more reliable is not available on an annual

13 Thus, the panel contains data for: Albania, Armenia, Azerbaijan, Belarus, Bulgaria, Croatia, Czech Republic, Estonia, Georgia, Hungary, Kazakhstan, Kyrgyz Republic, Latvia, Lithuania, Macedonia, Moldova, Poland, Romania, Russia, Slovakia, Slovenia, Tajikistan, Turkmenistan, Ukraine, Uzbekistan. 
basis, but we undertake a number of robustness checks (see subsection 5.2), which suggest that the very large output falls in the beginning of the transition period do not affect results unduly.

The right-hand side variables include consumer price inflation, I, measured as the annual percentage change of average consumer prices. EBRD (various issues) figures are used. The inflation rate can be interpreted as a measure of monetary stability and a function of stabilisation policies. Data for inflation are missing for 1989-90 for countries that were still part of the Soviet Union or Yugoslavia. To achieve a balanced panel, these missing values are replaced with the inflation figures for the Soviet Union or Yugoslavia as appropriate. This replacement has no material effect on the results. To avoid extreme inflation rate observations affecting the results unduly, the logarithmic transformation LI $=\log (100+\mathrm{I})$ is used.

Several transition economies have suffered civil unrest or international conflicts. The dummy, WAR, is equal to 1 for each year the country is engulfed in a serious domestic or international conflict. If the country is at peace, a value of 0 is used. ${ }^{14}$

We control for initial conditions in certain cases. Experimentation with individual country characteristics such as 1989 income level or the number of years under communism was unsuccessful as the variables were generally insignificant. We have instead chosen to control for initial conditions with two composite variables constructed by de Melo et al. (2001). INI1 captures the degree of macroeconomic distortions and unfamiliarity with market processes in society. INI2 measures overall economic development in terms of industrialisation (and possible over-industrialisation), pre-reform GDP and degree of urbanisation. Note that INI1 and INI2 are undated variables.

The right-hand variables of most importance to this study are indices measuring reform intensity. We have chosen to focus on the following indices constructed by the European Bank of Reconstruction and Development:

$\begin{array}{lll}\text { BRIRL } & - & \text { Banking reform and interest rate liberalisation } \\ \text { CP } & - & \text { Competition policy } \\ \text { GER } & - & \text { Governance and enterprise restructuring } \\ \text { LSP } & - & \text { Large-scale privatisation } \\ \text { PL } & - & \text { Price liberalisation } \\ \text { SMNB } & - & \text { Securities markets and non-bank financial institutions } \\ \text { SSP } & - & \text { Small-scale privatisation } \\ \text { TFES } & - & \text { Trade and foreign exchange system }\end{array}$

The EBRD indices capture three types of reforms. PL and TFES relate to liberalisation of the socialist economy. This occurred rapidly in many countries. SSP and LSP are privatisation indices measuring the transfer of production facilities to private owners. The indices ignore the specific privatisation methods used. The remaining four indices relate to restructuring and institution building. BRIRL and SMNB measure the emergence of financial markets and the efficiency of financial intermediation. GER refers to the governance structure of the firms and the degree of restructuring, in principle of private as well as state-owned firms. Finally, CP measures the legislation and

14 The dummy is constructed using information from: www.fas.org/man/dod-101/ops/war/, www.onwar.com/aced/index.htm and www.alertnet.org/thefacts/countryprofiles/. 
enforcement aimed at limiting misuse of monopolist power. See EBRD (2001, ch. 2) for a further discussion of the indices.

The indices are compiled from expert assessments of EBRD staff. An index score equal to 1 indicates no reform relative of a "standard" planned economy, while the maximum score 4.33 corresponds to a well-functioning market economy. The indices have been backdated to 1989 and data for the eight EBRD indices are thus available for the entire sample period 1989-2001 (EBRD, 2000, p. 31). ${ }^{15}$

Finally, a trend variable is employed in all regressions to "pick up" trended movements in G. The variable TREND is equal to 1 in 1989 and increases linearly to 13 in 2001 .

\section{Correlated reforms and principal components}

We employ a large set of variables to account for economic growth in 25 transition economies: the eight EBRD indices, logarithmic inflation, the conflict dummy and two variables capturing initial conditions. Table 1 shows the correlation matrix for the ten dated variables (i.e. excluding initial conditions) stacked for all 25 countries.

Table 1. Matrix of correlation coefficients for stacked variables

\begin{tabular}{|c|c|c|c|c|c|c|c|c|c|c|}
\hline & WAR & LI & BRIRL & $\mathrm{CP}$ & GER & LSP & PL & SMNB & SSP & TFES \\
\hline LI & 1 & 0.33 & -0.50 & -0.32 & -0.51 & -0.45 & -0.13 & -0.37 & -0.38 & -0.44 \\
\hline WAR & 0.33 & 1 & -0.27 & -0.30 & -0.30 & -0.31 & -0.18 & -0.27 & -0.26 & -0.28 \\
\hline BRIRL & -0.27 & -0.50 & 1 & 0.71 & 0.92 & 0.84 & 0.67 & 0.78 & 0.83 & 0.86 \\
\hline $\mathrm{CP}$ & -0.30 & -0.32 & 0.71 & 1 & 0.78 & 0.74 & 0.57 & 0.78 & 0.68 & 0.63 \\
\hline GER & -0.30 & -0.51 & 0.92 & 0.78 & 1 & 0.86 & 0.65 & 0.80 & 0.82 & 0.82 \\
\hline LSP & -0.31 & -0.45 & 0.84 & 0.74 & 0.86 & 1 & 0.67 & 0.75 & 0.84 & 0.80 \\
\hline PL & -0.18 & -0.13 & 0.67 & 0.57 & 0.65 & 0.67 & 1 & 0.53 & 0.79 & 0.80 \\
\hline SMNB & -0.27 & -0.37 & 0.78 & 0.78 & 0.80 & 0.75 & 0.53 & 1 & 0.70 & 0.66 \\
\hline SSP & -0.26 & -0.38 & 0.83 & 0.68 & 0.82 & 0.84 & 0.79 & 0.70 & 1 & 0.87 \\
\hline TFES & -0.28 & -0.44 & 0.86 & 0.63 & 0.82 & 0.80 & 0.80 & 0.66 & 0.87 & 1 \\
\hline
\end{tabular}

Stacked variables for 25 countries, 1989-2001.

A distinct correlation pattern is apparent. The conflict dummy is positively correlated with logarithmic inflation and negatively with all eight EBRD indices. Inflation is negatively correlated with all eight EBRD indices indicating that monetary stabilisation is positively correlated with the other reform indices. Most strikingly, all eight EBRD indices are positively and very strongly correlated with each other. The correlation coefficients lie, with few exceptions, within the interval 0.7-0.8.

The extent of correlation between the EBRD indices is problematic. Multicollinearity can lead to erroneous inference (see Havrylyshyn, 2001). ${ }^{16}$ It leads to imprecisely estimated parameters in growth regressions and makes it difficult to separate out the effects of different reforms as tests for exclusion of variables have low power. ${ }^{17}$

15 The EBRD kindly supplied country-specific variables for the period 1989-90, although they have yet to be published.

16 The multicollinearity problem was already acknowledged in Fischer et al. (1996b). Havrylyshyn and van Rooden (2000) provide examples of the consequences of multicollinearity in growth regressions.

17 A number of studies include an extra variable together with an overall reform variable. The new variable turns out to be highly significant, while the overall reform variable becomes insignificant. While 
We address the multicollinearity problem by using the principal components methodology, which generates new variables (principal components) as linear combinations of the original variables. The weights of the linear combinations (factor loadings) are chosen so that the new principal components are uncorrelated and so that the first principal component explains as much of the original variation as possible, the second principal component explains as much as possible of the remaining variation, etc. $^{18}$

We have chosen to calculate the principal components only for the eight EBRD indices. This choice is based on three considerations. First, LI and WAR are not very correlated with the EBRD indices. Second, the resulting principal components are easier to interpret when LI and WAR are excluded. Third, the variables LI and WAR are primarily included as control variables because the importance of both variables is firmly established in the literature.

The principal components are computed from the stacked reform indices, i.e. the values of each of the eight EBRD indices are stacked. This implies that the observations for all years weight evenly when the variance-covariance matrix (and hence, the principal components) are calculated.

Table 2. Principal components of eight policy reform variables

\begin{tabular}{lrrrrrrrr}
\hline & PC1 & PC2 & PC3 & PC4 & PC5 & PC6 & PC7 & PC8 \\
\hline Eigenvalue & 6.362 & 0.640 & 0.320 & 0.207 & 0.175 & 0.125 & 0.109 & 0.065 \\
\hline Variance proportion & 0.795 & 0.079 & 0.040 & 0.026 & 0.022 & 0.016 & 0.014 & 0.008 \\
\hline Loadings: & & & & & & & & \\
\hline BRIRL & 0.37 & -0.05 & -0.42 & 0.08 & 0.38 & 0.09 & -0.19 & 0.70 \\
\hline CP & 0.33 & -0.44 & 0.63 & -0.38 & 0.28 & -0.21 & 0.13 & 0.13 \\
\hline GER & 0.37 & -0.16 & -0.28 & -0.13 & 0.35 & 0.15 & -0.37 & -0.68 \\
\hline LSP & 0.37 & -0.05 & -0.16 & -0.49 & -0.59 & 0.46 & 0.18 & 0.07 \\
\hline PL & 0.32 & 0.59 & 0.53 & 0.23 & 0.08 & 0.41 & -0.19 & 0.01 \\
\hline SMNB & 0.34 & -0.49 & 0.07 & 0.73 & -0.32 & 0.05 & 0.09 & -0.06 \\
\hline SSP & 0.37 & 0.26 & -0.03 & -0.07 & -0.40 & -0.69 & -0.40 & 0.02 \\
\hline TFES & 0.36 & 0.34 & -0.20 & 0.08 & 0.21 & -0.24 & 0.76 & -0.17 \\
\hline Stacked & & & & & & &
\end{tabular}

Stacked variables for 25 countries, 1989-2001.

The result of the principal components analysis on the stacked EBRD indices is reported in Table 2. The principal components are labelled PC1, PC2,.., PC8. The upper panel shows the eigenvalues from the orthogonalisation of the sample correlation matrix and how much each principal component explains of the total variance of the primary EBRD indices (found as the eigenvalue of each principal component divided by the sum of eigenvalues). The lower panel shows the factor loadings used as weights to calculate the principal components as linear combinations of the original indices.

The principal components reveal clusters of reform policies. It explicates the joint structure of the reform indices and, thus, presents a condensed picture of the

one might conclude that the original reform variable has no impact on growth, this conclusion may well be erroneous in the presence of multicollinearity.

18 In technical terms the factor loadings used to calculate the uncorrelated principal components are found from an orthogonalising transformation of the sample correlation matrix. The eigenvalues from the orthogonalisation reflect the share of total variation explained by each principal component. 
different reform strategies undertaken. Some of the principal components have straightforward interpretations, while others have less intuitive renditions. The growth estimations in the next section reveal that only the following five principal components enter significantly:

- PC1 is broadly the sum of the eight reform indices, divided by 3 . The variable can be interpreted as broad-based reforms including liberalisation, privatisation and structural measures. PC1 captures $79.5 \%$ of total variation in the initial eight reform variables and, hence, it is not without merit that many studies use an overall reform variable simply calculated as the sum of the EBRD reform indices. We refer to PC1 as "broad-based reforms."

- PC2 has positive factor loadings for price liberalisation, market opening and small-scale privatisation. It has negative loadings for the rest of the EBRD indices, including the numerically large loadings for security markets and competition policy. PC2 captures what is sometimes called "early reforms" or "initial phase reforms" (EBRD (2002)), i.e. liberalisation and small-scale privatisation without accompanying structural reforms. PC2 is synonymous with "liberalisation."

- PC6 has large positive loadings for large-scale privatisation and price liberalisation and a numerically large negative loading for small-scale privatisation, i.e. a large PC6 indicates a large extent of large-scale privatisation relative to small-scale privatisation. PC6 will be referred to as "large-scale privatisation", but the principal component could just as well be defined as "lack of small-scale privatisation."

- PC7 is marginally significant in most of the growth regressions. PC7 has large positive factors loading for market opening and substantial negative loadings for small-scale privatisation and enterprise restructuring as PC7 captures an early market opening without privatisation or restructuring of production. PC7 is referred to as "early market opening."

- PC8 has a large positive loading for banking reforms and interest rate liberalisation, but a large negative loading for enterprise restructuring. PC8 captures a mismatch between banking and enterprise reforms and is referred to as "early bank liberalisation."

The use of principal components reveals a particular structure of the reform policies undertaken in transition economies. The reform cluster PC1, where liberalisation, privatisation and structural reforms are closely synchronised, captures $79.5 \%$ of the variation in the EBRD reform indices. This high share of variation is explained by the fact that all loadings are positive so PC1 retains the same trend as the underlying EBRD indices.

The remaining $20.5 \%$ of variation is explained by PC2, .., PC8. These principal components denote clusters where liberalisation, privatisation and structural reforms do not go hand-in-hand. They are examples of combinations of unsynchronised reforms. ${ }^{19}$ This turns out to be useful when exploring the issues of reform complementarity. For example, PC2 allows us to isolate the effect of liberalisation and small-scale privatisation

${ }^{19}$ We avoid use of the term "partial reforms" as it might be confused with the case where the level (or intensity) of individual reforms is limited. 
when no other reforms are pursued. Similarly, PC3, ..., PC8 represent different other clusters of unsynchronised reforms and allow us to consider the effect of these reform patterns.

The reform clusters will - in different forms - be used as right-hand side variables in the growth regressions in following sections. This use of principal components to identify clusters of reforms is relatively novel and involves a number of advantages. ${ }^{20}$ It addresses effectively the multicollinearity problem, which otherwise obscure inference testing of the importance of individual reform measures and of possible links between the measures.

The "traditional" method of detecting complementarities is to include products of different reform variables together with the reform variables themselves on the righthand side of the regression (e.g. Zinne et al. 2001). A significant and correctly signed parameter estimate to the multiplicative term is then interpreted as signifying a complementarity between the two reforms. This method has several drawbacks. First, it is essentially a joint test of both a possible complementarity and the specific multiplicative relationship between the two reform variables. Second, the test has very low power if one or both of the variables displays very little variation. Third, the multiplicative term could pick up possible non-linearities which are not stemming from reform complementarities. Fourth, the method has also low power if there are many correlated reform variables. If the multiplicative term of two reform variables is significant, then the multiplicative term of two other variables strongly correlated with the first two variables will likely also be correlated. Fifth, the method is generally best suited for cases where there are only few reform variables, which have to be interacted.

This discussion suggests that the method of using multiplicative terms is less useful in our case with many correlated reform variables. We propose instead using the reform clusters identified above as right-hand side variables. The eight clusters represent distinct combinations of reforms, which are interpretable as policy strategies, cf. above. The weights of the individual reforms in the clusters are determined so that the resulting clusters are uncorrelated, implying the clusters represent mutual exclusive reform packages. ${ }^{21}$ The uncorrelated reforms clusters also imply that (linear combinations of) all the EBRD indices can be entered as right-hand side variables in the regression model. We do not waste information by having to eliminate variables ex ante because of multicollinearity problems. We can instead use a standard general-to-specific method of elimination of insignificant variables when specifying our empirical model.

\section{Reforms and economic growth performance}

We can now regress the annual growth rate, $G$, on a set of right-hand variables. It is customary to include contemporaneous and one-year lagged variables on the righthand side. To facilitate interpretation, we implement this lag structure by including the

\footnotetext{
${ }^{20}$ Ahrens and Meurers (2002) also apply factor analysis to stacked right-hand variables, but their purpose, method and data set differ from ours. Sachs et al. (2000) apply a clustering method and de Melo et al. (2001) principal components, but in both cases only on data for initial conditions. Havrylyshyn and van Rooden (2000) use the principal components method on reform data for a single year.

21 Testing for complementarities implies ipso facto a cardinal comparison of variables, in this case reform indices. Using the standard method of multiplicative terms implies an essentially arbitrary combination of the selected indices, while the principal components methodology proposed in this paper weights all reform indices so that the resulting clusters are uncorrelated, i.e. no information need to be wasted in this case.
} 
contemporaneous first difference and the variable lagged one-year. The first difference of a variable is indicated by a pre-imposed $\Delta$. Employing a general-to-specific methodology, we initially enter the following variables on the right-hand side: $G(-1)$, TREND, WAR, $\triangle \mathrm{LI}, \mathrm{LI}(-1), \Delta \mathrm{PC} 1, \mathrm{PC} 1(-1), \ldots, \Delta \mathrm{PC} 8, \mathrm{PC} 8(-1)$.

The lagged growth rate $G(-1)$, the trend variable TREND and the conflict dummy WAR are essentially control variables, while the policy interest focuses on the terms involving logarithmic inflation LI and the principal components PC1, .., PC8. In most cases, we allow for country-specific fixed effects and exclude the variables capturing initial conditions, INI1 and INI2, from the regression.

The highly different growth paths among the countries in the sample may lead to cross-section heteroskedasticity. Consequently, we perform weighted least squares (WLS) estimation with cross-section weights derived from residual variances from a first-stage OLS estimation.

It is important to appreciate the "reduced form" nature of growth regressions for transition economies. In the absence of a firm theoretical foundation, the exercise merely exposes correlation patterns. Regarding their panel data regressions, Fischer et al. (1996b, p. 231) write, " “.. results should be viewed as a way of describing data, rather than reflecting deep structural relations." This makes it important to test the robustness of the results. Thus, we will later inter alia remove variables, change the dynamic structure and split the sample.

\subsection{Estimation results}

Even with our rich general specification, a large number of variables are significant at the 10\% level (i.e. have numerical $t$-values around or above 1.65): the war dummy, the inflation variables and one or both terms of principal components 1, 2, 6, 7 and 8. The general-to-specific model selection is implemented by successively eliminating the variable with the numerically lowest $t$-value to the point where all estimates are significant at the 5\% level. The resulting regression is shown in column (3.1) in Table 3.

The lagged growth rate and the trend variable are both strongly significant with positive parameters. These variables most likely reflect the contribution of omitted variables in the regression. However, the significant lagged growth rate may also be interpreted as the result of slow adjustment to changes in the right-hand side variables. Radulescu and Barlow (2002) discuss possible interpretations of this trend. Unsurprisingly, the parameter to the conflict dummy is negative and significant. The parameters to $(\log )$ inflation changes and lagged $(\log )$ inflation are precisely estimated and have negative signs.

Five principal components and in three cases their first differences survive the simplification procedure. The parameter to $\triangle \mathrm{PC} 1$ is negative, while the parameter to PC1 $(-1)$ is positive. Broad-based reforms have a short-term cost in form of lower growth the first year, but are beneficial for growth from the second year onwards. The parameter to $\triangle \mathrm{PC} 2$ is negative, while it is positive to PC2(-1). Liberalisation without accompanying reforms has a negative impact on growth in the very short term, but a positive impact in the "medium term", i.e. from the second year onwards. The parameters to $\triangle$ PC6 and PC6(-1) are both negative suggesting that accelerated largescale privatisation is bad for growth irrespective time horizon. The parameter to the term PC7(-1) is negative, although only marginally significant. Market opening without 
supporting reforms appears detrimental to growth. Finally, the parameter to PC8(-1) is also negative, indicating that a policy of early bank liberalisation without enterprise reform likely affects growth negatively.

Table 3. Panel data estimations of growth determinants

\begin{tabular}{|c|c|c|c|c|c|c|c|c|c|}
\hline & (3.1) & (3.2) & (3.3) & (3.4) & (3.5) & $(3.6)^{a}$ & $(3.7)^{\mathrm{a}}$ & $(3.8)$ & (3.9) \\
\hline \multirow[t]{2}{*}{$G(-1)$} & 0.23 & 0.19 & 0.30 & .. & 0.29 & 0.29 & 0.20 & 0.17 & 0.23 \\
\hline & (4.36) & (2.77) & (5.99) & & (5.71) & (2.73) & (2.22) & (2.64) & (3.81) \\
\hline \multirow[t]{2}{*}{ TREND } & 0.33 & 0.57 & 0.20 & 0.54 & 0.39 & 0.22 & 0.49 & 0.83 & 0.40 \\
\hline & (3.52) & (3.71) & (2.01) & $(5.57)$ & $(4.00)$ & (1.09) & (2.11) & (2.54) & (2.92) \\
\hline \multirow[t]{2}{*}{ WAR } & -6.36 & -6.24 & -6.02 & -8.06 & -6.38 & -7.96 & -4.82 & -5.84 & -9.20 \\
\hline & $(-3.74)$ & $(-2.96)$ & $(-3.30)$ & $(-5.34)$ & $(-3.30)$ & $(-2.53)$ & $(-1.79)$ & $(-2.80)$ & $(-6.06)$ \\
\hline \multirow[t]{2}{*}{$\Delta \mathrm{LI}$} & -2.29 & -2.71 & .. & -2.62 & -2.37 & -1.46 & -2.88 & -2.81 & -2.76 \\
\hline & $(-4.97)$ & $(-3.61)$ & & $(-5.52)$ & $(-4.32)$ & $(-1.88)$ & $(-4.71)$ & $(-6.08)$ & $(-4.75)$ \\
\hline \multirow[t]{2}{*}{ LI(-1) } & -3.00 & -2.62 & -1.97 & -4.18 & -2.44 & -1.26 & -2.84 & -3.63 & -4.26 \\
\hline & $(-6.40)$ & $(-3.33)$ & $(-5.04)$ & $(-10.49)$ & $(-4.89)$ & $(-1.05)$ & $(-2.69)$ & $(-6.10)$ & $(-6.91)$ \\
\hline \multirow[t]{2}{*}{$\Delta \mathrm{PC1}$} & -1.34 & -2.42 &.. & -1.68 & -1.32 & -1.99 & -2.13 & -2.04 & 1.74 \\
\hline & $(-3.02)$ & $(-2.81)$ & & $(-3.51)$ & $(-3.60)$ & $(-2.02)$ & $(-2.05)$ & $(-4.59)$ & (1.74) \\
\hline \multirow[t]{2}{*}{ PC1(-1) } & 0.73 & 0.27 & 1.35 & 0.53 & 0.44 & 0.73 & 0.41 & 0.56 & 0.04 \\
\hline & (4.15) & $(0.83)$ & (7.62) & (2.71) & (2.74) & (1.90) & $(0.83)$ & $(1.80)$ & $(0.07)$ \\
\hline \multirow[t]{2}{*}{$\triangle \mathrm{PC} 2$} & -1.43 & -1.38 & .. & -1.91 & -2.56 & -0.93 & -1.32 & -1.37 & 0.26 \\
\hline & $(-2.46)$ & $(-1.18)$ & & $(-3.04)$ & $(-5.21)$ & $(-0.62)$ & $(-1.13)$ & $(-2.08)$ & $(0.35)$ \\
\hline \multirow[t]{2}{*}{ PC2(-1) } & 2.56 & 3.78 & 3.28 & 2.38 & 1.14 & 4.85 & 3.62 & 2.63 & 1.09 \\
\hline & (4.72) & $(4.70)$ & (7.51) & (4.17) & (3.79) & (3.28) & (3.34) & $(3.50)$ & (1.25) \\
\hline \multirow[t]{2}{*}{$\triangle \mathrm{PC6}$} & -2.40 & -1.35 & .. & -2.10 & -1.47 & -1.67 & -1.49 & -3.24 & 2.21 \\
\hline & $(-3.00)$ & $(-0.89)$ & & $(-2.53)$ & $(-1.82)$ & $(-1.08)$ & $(-1.08)$ & $(-3.93)$ & (2.02) \\
\hline \multirow[t]{2}{*}{ PC6(-1) } & -2.97 & -3.49 & -0.47 & -3.99 & -1.24 & -3.91 & -2.88 & -4.48 & 2.18 \\
\hline & $(-2.91)$ & $(-2.03)$ & $(-0.59)$ & $(-3.99)$ & $(-1.51)$ & $(-1.49)$ & $(-1.62)$ & $(-3.06)$ & (1.40) \\
\hline \multirow[t]{2}{*}{ PC7(-1) } & -1.42 & -2.58 & -2.17 & -1.67 & -1.88 & -4.34 & -3.23 & 0.50 & -4.41 \\
\hline & $(-2.05)$ & $(-1.98)$ & $(-3.04)$ & $(-2.36)$ & $(-2.72)$ & $(-2.17)$ & $(-1.64)$ & $(0.65)$ & $(-5.02)$ \\
\hline \multirow[t]{2}{*}{ PC8(-1) } & -1.70 & -2.85 & -1.33 & -1.76 & -2.80 & -3.22 & -2.33 & -2.88 & -3.43 \\
\hline & $(-2.57)$ & $(-1.93)$ & $(-1.96)$ & $(-2.44)$ & $(-3.60)$ & $(-1.27)$ & $(-1.23)$ & $(-3.26)$ & $(-4.80)$ \\
\hline \multirow[t]{2}{*}{ Constant } &.. &.. &.. &.. & 10.38 &.. &.. &.. &.. \\
\hline & & & & & (3.89) & & & & \\
\hline \multirow[t]{2}{*}{ INI1 } & .. & .. & .. & .. & 0.25 & .. &.. & .. & .. \\
\hline & & & & & $(0.85)$ & & & & \\
\hline \multirow[t]{2}{*}{ INI2 } & .. & .. & .. & .. & -0.85 & .. & .. & .. & .. \\
\hline & & & & & $(-2.47)$ & & & & \\
\hline Method & WLS & OLS & WLS & WLS & WLS & GMM & GMM & WLS & $\overline{\text { WLS }}$ \\
\hline Sample & $90-01$ & $90-01$ & $90-01$ & $90-01$ & $90-01$ & 91-01 & 91-01 & $90-95$ & $96-01$ \\
\hline No. obs. & 300 & 300 & 300 & 300 & 300 & 300 & 300 & 150 & 150 \\
\hline $\mathbf{R}^{2}$ & 0.69 & 0.70 & 0.65 & 0.67 & 0.64 & .. &.. & 0.59 & 0.52 \\
\hline
\end{tabular}

The growth rate $G$ is left-hand variable. All estimations except (3.5) are fixed-effect regressions employing country dummies. t-statistics based on White Heteroskedasticity consistent standard errors are given in brackets and italics below parameter estimates.

a The estimated parameters are found from the differenced model using the Arellano-Bond procedure.

The first results are standard for the literature (see also the discussion in section 2). Outbreaks of war and high inflation are bad for growth, while overall broad-based 
reforms are good for growth. The new insights are mainly related to the estimates of the effects of unsynchronised reforms, i.e. the effects of PC2, PC6, PC7 and PC8.

\subsection{Robustness}

Column (3.2) in Table 3 presents the estimates obtained using ordinary pooled least squares (OLS), instead of WLS. All signs are retained, but the parameter estimate to PC1 $(-1)$ has fallen and is now insignificant. ${ }^{22}$ The estimated parameters and standard errors to $\triangle \mathrm{PC}$, PC6(-1), PC7(-1) and PC8(-1) have also changed to some extent. It seems appropriate whenever possible to use WLS.

As discussed above, endogeneity problems related to contemporary variables might bias the results. We have re-estimated regression (3.1) without $\Delta \mathrm{LI}, \Delta \mathrm{PC} 1, \Delta \mathrm{PC} 2$ and $\triangle$ PC6. The results reported in (3.3) show that the parameters to the lagged level of the variables $\mathrm{LI}(-1), \mathrm{PC} 1(-1), \mathrm{PC}(-1), \mathrm{PC} 6(-1), \mathrm{PC} 7(-1)$ and PC8(-1) have broadly retained their size and significance. In practice, the endogeneity problem associated with the variables based on EBRD indices is probably not serious as the indices are scored in the middle of the year when little information about the country's performance is known.

Outliers could influence results unduly, particularly the large negative growth rates registered for a number of CIS countries. For example, output contracted $52.6 \%$ in Armenia in 1992! This partly reflects the war in the country at that time, but may also be the result of underreporting. We replace the growth rate by the transformation $100 \cdot G /(100-G)$, which dampens the impact of large negative growth rates but has little impact on positive growth rates of "normal" size. The findings (not shown) are close to those in column (3.1), so data points with extreme growth rates do not "drive" the results. Moreover, experiments with transformations of other variables and inclusion of dummies to pick up outliers also show that the results are reasonably robust, partly because the equations are estimated using WLS.

It is relatively uncommon to include the lagged growth rate on the right-hand side of growth regressions for transition economies. ${ }^{23}$ To ensure that our results do not hinge on this specification, $G(-1)$ is excluded and the results shown in column (3.4). The main effect is that the parameter to TREND increases. With the exception of the parameter to PC1(-1), all other parameters increase somewhat numerically. This result is intuitive and the medium-term impacts are broadly the same as before as the dynamic effect from the lagged growth rate is now lacking. Removing the trend also has a negligible impact on the results (not shown).

To check the robustness of our results, we estimate the growth equation dropping the fixed effect dummies and including instead the two variables capturing initial conditions together with a constant. The results in column (3.5) are close to those in column (3.1) suggesting that the estimated impact of the reform variables is not a mirage caused by different initial conditions affecting both reform choices and growth results. INI2 is significant and has the expected negative sign, while INI1 is insignificant.

\footnotetext{
22 The problem of obtaining a precise estimate to $\mathrm{PC}(-1)$ will reappear in a number of the specifications used for robustness checks.

${ }^{23}$ Berg et al. (1999) include the lagged growth rate on the right-hand side of the regression, but find that it is insignificant.
} 
OLS-based estimation methods can yield biased estimates in dynamic panels due to correlation between the country-specific fixed effects and the error term. There is still no consensus on which estimation method to use in this case. The often-used ArellanoBond GMM method first eliminates country-specific effects by differencing the equation and then use lagged values of the level variables as GMM instruments. ${ }^{24}$

However, GMM estimation like the Arellano-Bond method gives rise to bias in small samples, in particular, when right-hand side variables are serially correlated. Indeed, Judson and Owen (1999) show that in a sample with few cross-sections and a short time horizon the Arellano-Bond method performs no better than the fixed-effect OLS estimator (although better than standard OLS without fixed effects). Other methods are likely to perform better, depending on the structure of data. Beck and Levine (2004) point out that estimates from the Arellano-Bond method could be strongly biased in small-sample dynamic panels with persistent right-hand side variables. Nerlove (2002) argues that the Arellano-Bond method is inappropriate in dynamic panels with a short time dimension and examines the properties of a number of other methods without finding any generally superior estimator. ${ }^{25}$

As a robustness check, we estimate the dynamic model with trend using the Arellano-Bond GMM method. In the first case, we only instrument the lagged growth rate, assuming that the contemporaneous right-hand variables $(\triangle \mathrm{LI}, \triangle \mathrm{PC} 1, \Delta \mathrm{PC} 2$ and $\Delta$ PC6) are weakly exogenous. The results using the Arellano-Bond one-step method are presented in column (3.6). Although some changes occur, the results in (3.6) are broadly in line with the results of the WLS estimation in (3.1) and with the OLS estimation in (3.3). (Note that the Arellano-Bond procedure implies that the sample is reduced one period.)

Column (3.7) shows the results when the contemporaneous variables $(\Delta \mathrm{LI}$, $\triangle \mathrm{PC} 1, \triangle \mathrm{PC} 2$ and $\triangle \mathrm{PC}$ ) are also instrumented using Arelleno-Bond level instruments. This should eliminate possible endogeneity biases from the contemporaneous righthand variables. Again, the changes are not dramatic.

The conclusion is that GMM estimation confirms the qualitative results obtained earlier. The estimated standard errors are generally larger for the GMM estimations than for the OLS/WLS estimations. This problem is to some extent related to the "weak instrument problem" causing the GMM estimators to be inefficient in small samples. ${ }^{26}$ We find, as do several other studies, that the GMM results are not fundamentally different from least-squares-based methods. They may, however, suffer from inference problems.

When the sample is split into two subperiods, some instability is revealed. The estimation results are shown for 1990-95 in column (3.10) and for 1996-2001 in column (3.11). The estimation results for the early subperiod correspond closely to the full sample results with the exception of the estimate to PC7(-1), which is positive, albeit insignificant. For the latter subperiod, a number of changes are noteworthy. First, the

${ }^{24}$ Instrumentation is required as the error term of the difference equation is still correlated with the lefthand side variable.

25 This is also reflected in e.g. Pattillo et al. (2002), where dynamic growth models are estimated. All results are presented using four different estimation techniques, including GMM.

26 The use of the Arellano-Bond method is not rejected. There is first-order autocorrelation in the residuals in the differenced model and the Sargan test does not reject the instruments. Nevertheless, the presence of serially correlated right-hand variables reduces the efficiency of the level instruments. The potential small-sample bias is an argument for avoiding a general-to-specific specification search using GMM. 
parameters to $\triangle \mathrm{PC} 1$ and $\triangle \mathrm{PC} 2$ are now positive, although none of the variables are significant at the $5 \%$ level. The short-term costs of reforms seem, at most, to be a feature of the early stages of transition. Second, the estimated parameters to PC1(-1) and PC2(-1) have dropped substantially. However, the changes to the parameters to $\triangle \mathrm{PC} 1$ and $\triangle \mathrm{PC} 2$ combined with the changes to PC1(-1) and PC2(-1) imply that the effects of the two reform clusters in the 2-4 years interval are broadly unchanged. What has changed is merely the adjustment dynamics. Third, $\triangle$ PC6 and PC6(-1) have changed sign, while PC7(-1) is highly significant in the late period. In sum, reforms do a better job of explaining growth at the beginning of the reform period than at the end. A number of studies reach this conclusion, e.g. Radulescu and Barlow (2002). This is consistent with the view that reforms change the structure of these economies, likely increasing the importance of traditional growth factors like physical and human capital accumulation.

The estimations reported employ "calendar time." Calendar time - as opposed to "transition time" - is chosen because it gives the longest possible sample, ensures more variation in both right-hand and left-hand variables and simplifies interpretation in certain cases. As a robustness check, most of the regressions in this paper have been reestimated using transition time using the correspondence suggested in Berg et al. (1999). The results (not shown) are broadly similar to those reported. The main difference is that the estimates to $\triangle \mathrm{PC} 1$ and $\triangle \mathrm{PC} 2$, although still negative, tend not to be significant at conventional levels. This result is broadly in line with the above finding that the negative and significant parameters to $\triangle \mathrm{PC} 1$ and $\triangle \mathrm{PC} 2$ are derived from the early part of the sample (which is shortened for many countries when transition time is used). ${ }^{27}$

\subsection{Results and discussion}

The broadly similar results obtained from many specifications suggest that several fairly robust conclusions can be drawn concerning the relationship between reforms and growth in transition countries. The control variables offer straightforward interpretations. Conflict situations affect growth negatively, while the lagged growth rate and a trend always attain positive signs.

Inflation and increasing inflation are negatively correlated with growth. The contemporaneous effect of inflation changes is negative even in the later half of the sample, i.e. there still appears to be no short-term Phillips curve relationship in the transition economies.

We find that broad-based reforms, as represented by principal component PC1, are good for growth in the medium term, while the short-term effect may be negative at the early stages of reform. The parameter to PC1(-1) has been estimated to values ranging from 0.22 to 0.73 (and 1.35 in an extremely under-parameterised model). This rather broad interval of estimates is somewhat inconvenient as PC1 captures the overall reform progress and different parameter sizes have different implications for the desirability of reforms. ${ }^{28}$

\footnotetext{
${ }^{27}$ Additional robustness tests can be found in the working paper version of this paper, Staehr (2003).

28 The result is, however, consistent with previous contributions, which have found a wide range of estimated parameter values to a broad index of reforms (see discussion in Radulescu and Barlow, 2002). Radulescu and Barlow (2002) use an extreme bounds analysis and show that the sum of the EBRD indices does not enter robustly in their growth regressions, i.e. the parameter and the significance of the
} 
Early reforms in the form of liberalisation and small-scale privatisation have a positive medium-term effect on growth even in the absence of other (mainly structural) reforms. Liberalisation and small-scale privatisation have a positive effect on growth even if structural reforms are less advanced. The short-term impact of early liberalisation appears to be negative at the early stages of reform.

A policy of large-scale privatisation and price liberalisation without small-scale privatisation and market opening has a negative impact on growth. The impact is contemporaneous, as well as medium-term. This result broadly confirms the finding in Zinnes et al. (2001) that privatisation without enterprise reforms leads to title change with little restructuring. Broadly similar results follow from the meta-analysis in Djankov and Murrell (2002) of approximately 100 empirical studies examining restructuring at the enterprise level. Fast privatisation of large firms with insufficient supporting reforms hold back firm restructuring and growth (see also Havrylyshyn, 2001). Note, however, that the result implies rapid small-scale privatisation is beneficial to growth even in the absence of large-scale privatisation and price liberalisation.

Early market opening without other reforms like small-scale privatisation and enterprise restructuring also seems detrimental to growth, at least in the latter part of transition. Figuratively, one might imagine foreign competition sweeping away domestic state-owned and unreconstructed producers. Crafts (2000) and IMF (1997) discuss preconditions necessary to ensure that market opening and international integration is beneficial to growth. Again, the reasoning can be reversed: a policy of small-scale privatisation and enterprise restructuring appear growth enhancing - even when not backed by market opening.

Finally, bank liberalisation without enterprise restructuring has a negative impact on growth, especially in the later stages of reform. An example of this might be the Czech experience in the mid-1990s, when excessive bank lending to non-restructured firms contributed to serious banking sector problems and unsatisfactory growth (see OECD, 1998 and 2000). The reverse interpretation is that enterprise restructuring is beneficial even in the absence of bank liberalisation.

\section{Speed of reforms}

The speed at which reforms should be introduced and implemented remains a controversial issue within transition economics. The debate also covers sequencing and reform complementary, as sequenced reforms may take longer to implement than broad-based reforms. This section focuses on the effect on growth of speed per se, i.e. the overall speed with which reforms are implemented. ${ }^{29}$

As noted in section 2, an argument for speedy reform exists when the reform level affects growth positively. Fast reforms would put the country on a higher path early on, allowing the country to enjoy higher growth for a longer period. In this sense, all estimations presented in section 5 suggest that broad-based reforms (PC1) or

parameter depend on other variables in the regressions. Fidrmuc (2003) also found that it is difficult to estimate the parameter to broad-based reforms precisely.

29 The speed of reforms is also important for objectives other than growth, e.g. distribution, regional development and medium-term political sustainability. These issues cannot be addressed in this framework. 
liberalisation (PC2) should be implemented rapidly. ${ }^{30}$ However, as argued in section 2 we are interested in effects on top of this level effect.

Testing directly for speed effects presents two challenges. We must specify precise and testable hypotheses, and then derive and implement tests of those hypotheses. Here, we consider two hypotheses. First, speed effects may affect the level of "pain" resulting from reforms in the short term. Second, the speed of reforms may affect medium-term growth, and therefore influence the selection of growth path. The shortterm hypothesis is examined by testing for possible convexity in the short-term reform costs. The medium-term hypothesis is tested by the construction of variables that capture, respectively, the divergence of the actual reform level from the trend level and indicator variables for a country's rate of reform.

\subsection{Non-linearities in short-term costs}

The estimations in section 5 implicitly assumed that short-term reform changes affect growth rates linearly. This assumption implies that the short-term costs of reforms are the same whether reforms are implemented quickly or done piecemeal over several years. However, possible convexities in the short-term impact would imply ceteris paribus that the level of transition "pain" might be lower in a slow reform regime.

The search for short-term convexities is narrowed to the first two principal components. The starting point for our search for convexities is regression (3.1) in Table 3. For ease of comparison, we repeat this regression in column (4.1) in Table 4. We test first for possible convexities in the link between $\triangle \mathrm{PC} 1$ and growth. $\triangle \mathrm{PC} 1$ is replaced by the transformation $(1.37+\Delta \mathrm{PC} 1)^{\alpha}$, where $\alpha$ is the parameter allowing for non-linear effects and 1.37 is added to ensure that the argument is always positive. We perform a grid search by varying $\alpha=0.1,0.2, \ldots$ searching for the $\alpha$-value leading to the parameter estimate with the highest $t$-value. The result is shown in column (4.2) in Table 4. A similar procedure is performed for $\triangle \mathrm{PC} 2$, with $\beta$ varied to give the most precise estimate of $(1.41+\Delta \mathrm{PC} 2)^{\beta}$. The result appears in column (4.3).

For the term containing $\triangle \mathrm{PC} 1$ the $t$-value was maximised for $\alpha=12.3$ while the $t$-value for the term containing $\triangle \mathrm{PC} 2$ was maximised for $\beta=1.6$. There seems to be a high degree of convexity in the short-term growth costs of broad-based reform and a moderate degree in the liberalisation term.

The results are obtained in spite of the test being biased against detecting nonlinear effects as only linear variables were used in the specification search. Still, the test has little power. In the specification shown in (4.2) we have added $\triangle \mathrm{PC} 1$ as a separate right-hand side variable to "compete" with $(1.37+\Delta \mathrm{PC} 1)^{12.3}$.

The parameters to both $(1.37+\Delta \mathrm{PC} 1)^{12.3}$ and $\Delta \mathrm{PC} 1$ are negative, but insignificant. A Wald test cannot reject the joint hypothesis that the parameter to $(1.37+\Delta \mathrm{PC} 1)^{12.3}$ is 0 and the parameter to $\Delta \mathrm{PC} 1$ is -2.29 (as in the original specification). We conclude that, although the convex specification yields a slightly more precise parameter estimate, the difference is not statistically significant. The same holds for the convex specification of $\triangle \mathrm{PC} 2$.

${ }^{30}$ Naturally, the opposite holds for the unsynchronised reforms of the types captured by PC6, PC7 and PC8. 
Table 4. Speed effects in panel data estimations of growth determinants

\begin{tabular}{|c|c|c|c|c|c|c|}
\hline & $(4.1)^{\mathrm{a}}$ & (4.2) & (4.3) & (4.4) & (4.5) & (4.6) \\
\hline \multirow[t]{2}{*}{$G(-1)$} & 0.23 & 0.26 & 0.23 & 0.32 & 0.27 & 0.27 \\
\hline & $(4.36)$ & (4.98) & $(4.36)$ & (5.53) & (5.49) & (5.68) \\
\hline \multirow[t]{2}{*}{ TREND } & 0.33 & 0.30 & 0.33 & 0.42 & 0.60 & 0.70 \\
\hline & (3.52) & (3.42) & (3.52) & (2.71) & (5.41) & (6.43) \\
\hline \multirow[t]{2}{*}{ WAR } & -6.36 & -5.94 & -6.42 & -3.14 & -6.47 & -6.33 \\
\hline & $(-3.74)$ & $(-3.87)$ & $(-3.81)$ & $(-1.55)$ & $(-3.30)$ & $(-3.19)$ \\
\hline \multirow[t]{2}{*}{$\Delta \mathrm{LI}$} & -2.29 & -2.32 & -2.22 & -1.32 & -2.43 & -2.43 \\
\hline & $(-4.97)$ & $(-5.59)$ & $(-4.86)$ & $(-2.28)$ & $(-4.41)$ & $(-4.45)$ \\
\hline \multirow[t]{2}{*}{$\mathrm{LI}(-1)$} & -3.00 & -3.10 & -2.98 & -2.19 & -2.62 & -2.65 \\
\hline & $(-6.40)$ & $(-7.41)$ & $(-6.42)$ & $(-3.24)$ & $(-5.18)$ & $(-5.36)$ \\
\hline \multirow[t]{2}{*}{$\Delta \mathrm{PC} 1$} & -1.34 & .. & -1.17 & -0.01 & -1.51 & -1.62 \\
\hline & $(-3.02)$ & & $(-2.54)$ & $(-0.02)$ & $(-4.20)$ & $(-5.02)$ \\
\hline \multirow[t]{2}{*}{ PC1(-1) } & 0.73 & 0.82 & 0.73 & 0.23 & 0.36 & 0.39 \\
\hline & $(4.15)$ & $(4.96)$ & $(4.12)$ & $(0.53)$ & (2.32) & $(2.76)$ \\
\hline \multirow[t]{2}{*}{$\overline{\Delta \mathrm{PC} 2}$} & -1.43 & -1.23 & .. & 1.42 & -2.49 & -2.47 \\
\hline & $(-2.46)$ & $(-2.06)$ & & (1.93) & $(-5.11)$ & $(-5.51)$ \\
\hline \multirow[t]{2}{*}{ PC2(-1) } & 2.56 & 2.38 & 2.46 & 3.51 & 1.08 & 0.80 \\
\hline & $(4.72)$ & (4.88) & $(4.50)$ & $(4.54)$ & $(3.50)$ & (2.60) \\
\hline \multirow[t]{2}{*}{$\triangle \mathrm{PC} 6$} & -2.40 & -2.91 & -2.41 & -2.27 & -1.37 & -1.42 \\
\hline & $(-3.00)$ & $(-3.69)$ & $(-3.02$ & $(-2.07)$ & $(-1.71)$ & $(-1.85)$ \\
\hline \multirow[t]{2}{*}{ PC6(-1) } & -2.97 & -3.12 & -3.01 & -1.69 & -1.28 & -1.15 \\
\hline & $(-2.91)$ & $(-3.19)$ & $(-2.95)$ & $(-1.15)$ & $(-1.61)$ & $(-1.50)$ \\
\hline \multirow[t]{2}{*}{ PC7(-1) } & -1.42 & -1.21 & -1.47 & -2.80 & -1.87 & -1.70 \\
\hline & $(-2.05)$ & $(-1.77)$ & $(-2.09)$ & $(-2.69)$ & $(-2.80)$ & $(-2.51)$ \\
\hline \multirow[t]{2}{*}{ PC8(-1) } & -1.70 & -1.16 & -1.65 & -1.05 & -2.17 & -2.08 \\
\hline & $(-2.57)$ & $(-1.73)$ & $(-2.48)$ & $(-1.24)$ & $(-2.73)$ & $(-2.76)$ \\
\hline \multirow[t]{2}{*}{$(1.37+\Delta \mathrm{PC} 1)^{12.3}$} & .. & $-3.13 \cdot 10^{-8}$ & .. & .. & .. & $\overline{. .}$ \\
\hline & & $(-4.36)$ & & & & \\
\hline \multirow[t]{2}{*}{$(1.41+\Delta \mathrm{PC} 2)^{1.6}$} & .. & .. & -0.8 & .. &.. & .. \\
\hline & & & $(-2.62)$ & & & \\
\hline \multirow[t]{2}{*}{ PC1SP } &.. &.. & .. & 0.12 &.. & .. \\
\hline & & & & $(0.62)$ & & \\
\hline \multirow[t]{2}{*}{ Constant } & .. & .. & .. & .. & 10.38 & 10.06 \\
\hline & & & & & (3.92) & (3.87) \\
\hline \multirow[t]{2}{*}{ INI1 } & .. &.. &.. & .. & 0.03 & .. \\
\hline & & & & & $(0.09)$ & \\
\hline \multirow[t]{2}{*}{ INI2 } & .. & .. & .. & .. & -0.98 & .. \\
\hline & & & & & $(-2.90)$ & \\
\hline \multirow[t]{2}{*}{ YEAR } & .. &.. & .. & .. & -0.54 & .. \\
\hline & & & & & $(-4.14)$ & \\
\hline \multirow[t]{2}{*}{ FAST } &.. &.. &.. &.. &. & -3.77 \\
\hline & & & & & & $(-6.88)$ \\
\hline SLOW & .. & .. & .. & .. & .. & -3.12 \\
\hline & & & & & & $(-5.03)$ \\
\hline Method & WLS & WLS & WLS & WLS & WLS & WLS \\
\hline Sample & $90-01$ & $90-01$ & 90-01 & 93-01 & $90-01$ & $90-01$ \\
\hline No. observations & 300 & 300 & 300 & 225 & 300 & 300 \\
\hline $\mathbf{R}^{2}$ & 0.69 & 0.68 & 0.69 & 0.62 & 0.66 & 0.66 \\
\hline
\end{tabular}

The growth rate $G$ is left-hand variable. -statistics based on White Heteroskedasticity consistent standard errors are given in brackets and italics below parameter estimates.

${ }^{a}$ For ease of comparison, column (4.1) repeats column (3.1) from Table 3. 


\subsection{Divergence from trend reform path}

We construct a variable that directly reflects the speed of reforms based on a suggestion in Berg et al. (1999). The idea is to calculate the trend reform level during a fixed time window, and then compare the actual reform level with the calculated trend value during the early part of the window. The higher the early reform level is above trend level, the speedier the implementation of reforms.

The implementation speed of broad-based reforms is considered within a fouryear window. We follow the convention in econometrics and use no time indication of the current realisation of a variable. We use $\tau$ to indicate years from current year. Thus, $\tau$ $=0$ indicates the current year, $\tau=-1$ indicates a one year lag, $\tau=-2$ indicates a two year lag, etc. With this notation, the contemporaneous reform level is PC1 and the reform level in year $\tau$, i.e. the reform level lagged $\tau$ years, is $\operatorname{PC1}(\tau)$.

We consider a four-year window preceding the current year. The total change in the reform index during the four year period is [PC1 - PC1(-4)] and the average annual change is $[\mathrm{PC} 1-\mathrm{PC} 1(-4)] / 4$. Accordingly, the expected trend reform level for any year in the four-year window preceding the current year is:

$$
\operatorname{EPC} 1(\tau)=\operatorname{PC} 1(-4)+(4+\tau) \cdot \operatorname{PC} 1-\operatorname{PC} 1(-4)] / 4,
$$

where $\tau=-4, \ldots,-1$. For $\tau=-4, \operatorname{EPC} 1(\tau)=\operatorname{PC} 1(\tau)$, while $\operatorname{EPC} 1(\tau)$ increases linearly with the annual rate of reform change for $\tau=-3,-2,-1$. The speed variable PC1SP is the sum of the differences between the actual and the trend reform level for years $\tau=-3$ and $\tau=-2$ :

$$
\mathrm{PC} 1 \mathrm{SP}=[\mathrm{PC} 1(-3)-\operatorname{EPC} 1(-3)]+[\mathrm{PC} 1(-2)-\operatorname{EPC} 1(-2)]
$$

PC1SP is added to specification (3.1) with the result shown in column (4.4) in Table 4. Note that the sample period has changed as PC1SP absorbs three years of the sample. The parameter to PC1SP is positive, but insignificant. ${ }^{31}$ It should be noted, however, that the regression contains many variables, which could make it difficult for PC1SP to attain significance. The partial correlation between G and PC1SP is positive and highly significant. Still, experiments with different samples, non-linear transformations and lagged values of PC1SP show that no stable relationship exists. On the suspicion of asymmetric effects, we split PC1SP into two variables respectively containing positive and negative values, but the results (not shown) were again inconclusive. Similar exercises using the liberalisation cluster (PC2) fail to yield any consistent results.

\subsection{Scoring of reform speed}

Finally, we apply methods derived from Wolf (1999) to test for speed effects. Initially, the number of years from the start of the reform process (i.e. year 0 using

31 The parameter to $\triangle \mathrm{PC1}$ is now insignificant. This is the consequence of the shorter sample (also see (3.9) in Table 3) and the exclusion of PC1SP. 
transition time) until PC1 has increased by 4 is counted. ${ }^{32}$ This number (score) would be e.g. 2 for the Czech Republic and Estonia, 4 for Hungary and Moldova, and 7 for Bulgaria and Croatia. For some countries, e.g. Belarus and Macedonia, PC1 does not increase by 4 units within by 2001 .

The variable YEAR is constructed as follows: For 1989-1997 it contains zeros; for 1998-2001 it contains the speed score provided the score is less than 8, otherwise zero. The construction of YEAR with zeros until 1998 implies that only medium-term effects of the speed score are captured and ensures that the measure of reform speed does not affect growth before reforms are actually implemented. ${ }^{33}$

We include YEAR in regression (3.5) with a constant term and controls for initial conditions. (Fixed effects estimation cannot be used when YEAR is included.) The result is shown in column (4.5) in Table 4. The estimated parameter is negative and significant, indicating that reform speed is positively correlated with growth, i.e. rapid reform is associated with higher medium-term growth.

Another test separates the transition countries into three groups. The first group consists of countries undertaking fast reforms (YEAR $\leq 3$ ), the second group consists of countries undertaking gradual reforms $(4 \leq$ YEAR $\leq 7)$ and the third group contains reform-resistant laggards (YEAR $\geq 8$ ). The dummy FAST has zeros for 1989-97 and ones for 1998-2001 for all countries in the first group. The dummy SLOW has zeros for 1989-97 and ones for countries in the second group. Column (4.6) in Table 4 shows the result of adding these two dummy variables to regression (3.5). Both have negative (and significant) parameters. The parameter to FAST is smaller than to SLOW, which may indicate that slow reforms were beneficial to growth. However, the Wald test cannot reject the hypothesis that the two parameters are identical.

The method of directly inserting the variables YEAR or FAST and SLOW into the growth regression did not provide firm evidence on the effect of speed. However, there is no evidence that speedy reforms hampered medium-term growth.

\subsection{Discussion}

Early reforms allow more years in which the transition country can reap the benefits. Beyond this trivial finding, the panel data methodology employed in this paper does not provide strong arguments for or against rapid reform. The short-term cost of reforms might be larger when implemented in bulk, but the effect is small and insignificant. The medium-term growth effects of rapid reform are uncertain, but rapid reforms appear unlikely to hamper growth. In sum, the speed of reforms does not appear to a quantitatively substantial impact on growth over and above the level effect. This result is in conflict with the conclusions in World Bank (1996) and Berg et al. (1999), but is broadly in line with Wolf (1999).

32 For a country starting with all reform indices at their lowest level (e.g. most countries emerging from the Soviet Union), an increase of PC1 equal to 4 signifies that the country is halfway to a well-developed market economy.

${ }^{33}$ It also implies that the variable YEAR only contributes to explaining growth in the last four years of the sample 1990-2001, i.e. the part of the sample where the other right-hand variables are relative less effective. 


\section{Final comments}

A novel feature of this paper was the use of principal component clustering of the EBRD reform indices to infer the structure of reform in transition economies. A cluster of synchronised, broad-based reforms, i.e. liberalisation, privatisation and structural reforms, covers $79.5 \%$ of all variation in the initial EBRD reform indices. A cluster of liberalisation and small-scale reforms without other reforms explains $7.9 \%$ of the variation, while six other clusters of unsynchronised reforms span the remaining $12.6 \%$.

The growth regressions included the reform clusters, inflation terms and control variables. As in most other studies, inflation was found to be detrimental to growth. Synchronised, broad-based reforms had a positive impact on growth in the medium term, with a negative short-term effect at the early stages of reform. Also a policy of liberalisation and small-scale privatisation without accompanying structural reforms were shown to have a positive effect (again, with a possible early negative short-term effect). Accelerated large-scale privatisation without small-scale privatisation and structural reforms were found likely to harm growth, both in the short and the medium term.

Conversely, small-scale privatisation without large-scale privatisation appears beneficial to growth. A less certain result is that market opening and price liberalisation without accompanying privatisation and enterprise reforms appear correlated with lower growth, but this effect stems primarily for the most recent period. Reversing this result, privatisation and restructuring without market opening may be good for growth. Finally, bank liberalisation without enterprise restructuring might be harmful, while enterprise reforms without bank liberalisation may increase growth.

Effects from the speed of reforms are mostly absent, with the exception that early reforms leave the transition country a longer period in which to reap the benefits of reforms. Possible negative short-term effects of rapid reforms are likely to be modest, and could be balanced by possible positive medium-term effects. The broad overall conclusion is that speed per se has no discernible impact on growth. introduction?

Finally, what can we now say about the three questions raised in the

First, the analysis revealed a complex pattern of reform complementarities with notable implications for the sequencing of reforms. Balanced, wide-ranging reforms based on simultaneous progress in liberalisation, privatisation and structural reforms are favourable to growth, and hence suggest a mutually reinforcing effect of various reform elements.

Liberalisation combined with small-scale privatisation is beneficial even in the absence of other reforms. In this case, unsynchronised reforms produce positive growth effects. Thus, liberalisation and small-scale privatisation are not perfectly complementary to deeper reforms such as large-scale privatisation and structural reforms. A sequenced reform policy that stresses liberalisation and small-scale privatisation is beneficial. Early, "easy" reforms should therefore not be postponed in the absence of a comprehensive reform strategy.

A number of unsynchronised reform packages proved detrimental to growth. Sequenced policy packages involving large-scale privatisation without small-scale privatisation, market opening without accompanying reforms, and bank liberalisation without enterprise restructuring lead to lower growth in the short and/or medium term. Conversely, a "reversal" of the policy mix would produce packages beneficial to growth. 
In sum, the statistically significant parameters to a number of unsynchronised reform clusters support the view that reforms need to be fine-tuned to take into account complex interactions among reforms.

Second, we asked which reforms are of foremost importance. Within the set of variables used in this paper and using a broad brush, a number of variables stand out. Inflation stabilisation repeatedly proved important. Price liberalisation, small-scale privatisation, enterprise restructuring (and to a lesser degree trade opening) were generally important in many different combinations with other reforms. Large-scale privatisation, financial sector reforms and market regulation mainly proved beneficial when they were part of a larger, more comprehensive reform packages. These results seem to support the view that reform policies are crucial - even countries that fail to attempt deep structural changes can gain from reforms. These findings are broadly in line with the findings in Havrylyshyn and van Rooden (2000). As a caveat, we note that only a few variables included in our analysis reflect currently popular themes such as institutional quality and social capital.

Third, the finding that speed per se is of little importance for growth seems to favour relatively rapid implementation of reforms due to the level effect. However, this finding also implies there is no direct loss from slowing reforms when it is necessary to get content or sequencing right.

These results probably disappoint supporters of big-bang as well as supporters of gradualism, as they provide no unequivocal support for either view. If it is any consolation to the gradualists, reform sequencing appears to be important, and reforms should preferably progress synchronously. Certain sequenced reform paths are clearly counterproductive. Likewise, for the big-bang supporters, initial phase reforms are beneficial, even in the absence of deeper reforms. Moreover, fast reforms appear generally beneficial. Thus, there is no clear-cut transition strategy that provides the best results for countries endeavouring to convert a centrally planned economy into a market economy. There are only policy choices - some better than others - and certain strategies that should be avoided.

\section{References}

Ahrens J., Meurers M. (2002), 'How Governance Affects the Quality of Policy Reform and Economic Performance: New Evidence for Economies in Transition', Journal for Institutional Innovation, Development and Transition, 6, 35-56.

Aslund A. (2002): Building Capitalism. The Transformation of the Former Soviet Bloc, Cambridge University Press, Cambridge.

Aziz J., Wescott R. (1997), 'Policy Complementarities and the Washington Consensus', IMF Working Paper No.118.

Beck T., Levine R. (2004), 'Stock Markets, Banks, and Growth: Panel Evidence', Journal of Banking and Finance, 28, 423-442.

Berg A., Borensztein E., Sahay R., Zettelmeyer J. (1999), 'The Evolution of Output in the Transition Economies: Explaining the Differences', IMF Working Paper No.73.

Blanchard O., Dornbusch R., Krugman P., Layard R., Summers L. (1991), Reform in Eastern Europe, MIT Press, Cambridge, MA.

Campos N., Coricelli F. (2002), 'Growth in Transition: What We Know, What We Don't, and What We Should', Journal of Economic Literature, 90, 793-836. 
Correa R. (2002), 'The Washington Consensus in Latin America: A Quantitative Evaluation', mimeo, San Francisco de Quito University, Ecuador.

Crafts N. (2000), 'Globalization and Growth in the Twentieth Century', in Prasad, E. (ed.) Supporting Studies for the World Economic Outlook, International Monetary Fund, Washington, DC.

de Melo M., Denizer C., Gelb A. (1997), 'From Plan to Market: Patterns of Transition', in Blejer M., Skreb M. (eds.), Macroeconomic Stabilization in Transition Economies, Cambridge University Press, Cambridge.

de Melo M., Denizer C., Gelb A. (2001), 'Circumstance and Choice: The Role of Initial Conditions and Policies in Transition Economies', World Bank Economic Review, 15, 1-31.

Djankov S., Murrell P. (2002), 'Enterprise Restructuring in Transition: A Quantitative Survey', Journal of Economic Literature, 90, 739-792.

EBRD (1999-2004), Transition Report, European Bank for Reconstruction and Development.

Fidrmuc J. (2003), 'Economic Reform, Democracy and Growth during Post Communist Transition', European Journal of Political Economy, 19, 583-604.

Fischer S., Gelb A. (1991), 'The Process of Socialist Economic Transformation', Journal of Economic Perspectives, 5, 91-105.

Fischer S., Sahay R. (2000), 'The Transition Economies After Ten Years', IMF Working Paper No.30.

Fischer S., Sahay R., Vegh C. (1996a), 'Stabilization and Growth in Transition Economies: The Early Experience', Journal of Economic Perspectives, 10, 45-66.

Fischer S., Sahay R., Vegh C. (1996b), 'Economies in Transition: The Beginnings of Growth', American Economic Review, 86, 229-233.

Havrylyshyn O., van Rooden R. (2000), 'Institutions Matter in Transition, but so do Policies', IMF Working Paper No.70.

Havrylyshyn O. (2001), 'Recovery and Growth in Transition: A Decade of Evidence', IMF Staff Paper, 48, 53-87.

Havrylyshyn O., Izvorski I., van Rooden R (1998), 'Recovery and Growth in Transition Economies 1990-97: A Stylized Regression Analysis', IMF Working Paper No.141.

Heybey B., Murrell P. (1999), 'The Relationship Between Economic Growth and the Speed of Liberalization During the Transition', Policy Reform, 3, 121-37.

IMF (1997), World Economic Outlook. Globalization. Opportunities and Challenges, May, chapter IV.

IMF (2000), World Economic Outlook. Focus on Transition Economies, October, chapter III.

Judson R., Owen A. (1999), 'Estimating Dynamic Panel Data Models: A Practical Guide for Macroeconomists', Economics Letters, 65, 9-15.

Nerlove M. (2002), 'Properties of Alternative Estimators of Dynamic Panel Models: An Empirical Analysis of Cross-Country Data for the Study of Economic Growth', in Nerlove, M.: Essays in Panel Data Econometrics, Cambridge University Press, Cambridge.

Nsouli S., Rached M., Funke N. (2002), 'The Speed of Adjustment and the Sequencing of Economic Reforms: Issues and Guidelines for Policymakers', IMF Working Paper No.132.

OECD (1998), OECD Economic Surveys. Cžech Republic, May, OECD.

OECD (2000), OECD Economic Surveys. Czech Republic, February, OECD.

Pattillo C., Poirson H., Ricca L. (2002), 'External Debt and Growth', IMF Working Paper No.69.

Radulescu R., Barlow D. (2002), 'The Relation between Policies and Growth in Transition Countries', Economics of Transition, 10, 719-745.

Roland G. (2001), 'Ten Years After ... Transition and Economics', IMF Staff Papers, 48, 29-52. 
Sachs J., Zinnes G., Eilat Y. (2000), 'Patterns of Economic Reform and its Determinants in Transition Economies: 1990-1998', Harvard Institute for International Development CAER II Discussion Paper No. 61.

Staehr, K. (2003), 'Reforms and Economic Growth in Transition Economies: Complementarity, Sequencing and Speed', BOFIT Discussion Paper No.1.

Stiglitz J. (2001), 'Whither Reform? Ten Years of Transition', in Pleskovic B., Stiglitz J. (eds.), World Bank Annual Bank Conference on Development Economics 1999, World Bank, Washington, DC.

Wacziarg R. (2002), 'Review of Easterly's The Elusive Quest for Growth', Journal of Economic Literature, 90, 907-918.

Wolf H. (1999), 'Transition Strategies: Choices and Outcomes', Princeton Studies in International Finance No.85.

World Bank (1996), World Development Report 1996: From Plan to Market, World Bank, Washington DC.

World Bank (2002), Transition. The First Ten Years. Analysis and Lessons for Eastern Europe and the former Soviet Union, World Bank, Washington DC.

Zinnes C., Eilat Y., Sachs J. (2001), 'The Gains from Privatization in Transition Economies: Is 'Change of Ownership' Enough?', IMF Staff Papers, 48, 146-169. 